\title{
STRATEGIC SOLUTIONS FOR CORPORATE RESTRUCTURING
}

\author{
Juozas BIVAINIS ${ }^{1}$ and Andrius TAMOŠIŪNAS ${ }^{2}$ \\ 1 Department of Social Economics and Management, Vilnius Gediminas Technical University, \\ Sauletekio al. 11, LT-10223 Vilnius, Lithuania \\ Tel.: (370 5) 2744876; e-mail:vvfsevk@vv.vtu.lt \\ 2 Central Project Management Agency, J. Tumas-Vaižgantas str. 8A/2, LT-01512 Vilnius, Lithuania \\ Tel.: (370 5) 2514378; e-mail: a.tamosiunas@cpma.lt
}

Received 18 November 2003; accepted 24 February 2004

\begin{abstract}
The paper analyses solutions of corporate restructuring, specifying the techniques of their application in the context of improvement of strategic management, rationalization of corporate management functions as well as measures to control the restructuring process.

The benefit of application of the proposed corporate restructuring solutions is revealed. Greater possibilities to rationalize the restructuring process, use of human potential, material and financial assets, other relevant strategic corporate property, to develop resources of an enterprise and thus to reach greater competitiveness of enterprises are created.
\end{abstract}

KEYWORDS: Corporate Restructuring; Strategic Management; Assets; Model; Measures

\section{INTRODUCTION}

Processes of restructuring of enterprises take place continuously in the countries of market economy. This is a natural process, which is stimulated by competition, market changes, and processes of integration and globalization of countries' economic systems.

Corporate restructuring processes in Lithuania are related to the transformation and integration processes of Lithuania's economy into the EU and the entire world economic systems. These processes had virtually affected all the sectors of Lithuania's economy. Restructuring process is stimulated by the increasing competition of business entities, the desire of each of them to maintain or even strengthen positions in highly competitive domestic and foreign markets.

Many Lithuanian enterprises were not able to modernize their activity and had either incurred economic difficulties or, having not evaluated the impact of fast changes of exter- nal conditions, achieved the expected restructuring results in the last decade of the country's economic system transformation.

These factors reveal the necessity to improve in a complex manner the management of enterprise restructuring. It needs a mechanism, which would give a possibility to an enterprise, acting in the rapidly changing environment, to rationalize the management of the combination of its human, material and financial resources and other relevant strategic property thus increasing the competitiveness of an enterprise.

Scientific Problem. The topic of corporate restructuring has been analyzed in various aspects by Ansoff [3], Rock [24], Greiner [18], Bower [10], Bosas [9], Bivainis [6, 7]. The scientific research towards the corporate restructuring accomplished in the country is fragmentary. There was no research made until now, the results of which could set the background for preparation and effective implementation of the economically justified complex solutions 
for corporate restructuring.

The Purpose of the Research is to propose the solutions for corporate restructuring which would let enterprises rationalize the management of restructuring process, the use of human, material and financial resources as well as other relevant strategic property, and develop possibilities of the use of enterprise potential reaching the competitiveness increase.

The Object of the Scientific Research is corporate restructuring as a radical and rational way of reconstruction of enterprises in order to increase the competitiveness of enterprises.

Methods of the investigations are comparative analysis of the problem, synthesis, modeling.

Scientific Novelty and Practical Benefit. The solutions for corporate restructuring are proposed in the paper. They create the possibility to rationalize restructuring processes and the use of human, material and financial potentials of an enterprise.

\section{CORPORATE RESTRUCTURING PROGRAMIME}

Corporate restructuring is the strategic management technique used to rationalize the enterprise activity and resulting in essential changes of corporate strategy and structure, pursuing to increase enterprise competitiveness in clearly defined time outlook [6, 7]. In this context we can state that corporate restructuring is based on the programme (or plan) of the objectives and their tasks for changing the enterprise activities, covering the complex of the measures and ways thereof, which due to its content are similar to the programme for the implementation of the corporate strategy as at tactical and strategic levels of the enterprise management $[2,3,6,9,10]$.

The following aspects are considered as the main ones with respect to the content of the corporate restructuring programme $[4,6,11$, 12]:

- the enterprise activity objectives (long and short-term);
- the alternatives of restructuring strategic decisions, restructuring techniques, validity of their application;

- the demand of human, material and financial resources and other property necessary for their application;

- the possible benefit of the strategy to the enterprise (if the latter were implemented) and risk factors which may reduce this benefit;

- the changes of enterprise organizational management as well as assets/property structures to be made in order to implement the strategy;

- the necessary changes of human resources (reduction of staff number, employing, the change of functions, authority and responsibility);

- the changes of functional strategies to be done (concentrating on departments and divisions of the lowest efficiency level);

- the forecast of restructured enterprise activity results and their comparison with expected results of the competitors activity;

- restructuring strategy implementation plan, indicating the tasks to be solved and persons, divisions responsible for the execution of the tasks as well as the time schedules thereof.

One of the first tasks of restructuring programme implementation is to renew the strategic management system. The second task is to rationalize the management of enterprise in terms of efficiency increase of corporate strategy and its functional strategies. The subsequent thing thereof is execution of programme tasks at the level of enterprise functional departments and business units $[8,19$, $21,22,25]$.

\section{IMPROVEMENT OF STRATEGIC MANAGEMENT}

The purpose of strategic management system improvement task is to rationalize execution of the main strategic management functions of an enterprise (corporate management, 
production, finance, marketing, innovation and human resources management) at operational, tactical and strategic levels. In order to solve this task it is necessary to select the set of measures and techniques letting to form the combination of human, material and financial resources, the efficiency of which at operational, tactical and strategic levels would exceed the efficiency level of strategic management of not restructured enterprise. In this context the efficiency of strategic management (E) formally could be expressed in the following manner:

$$
E=f\left(U_{1}, U_{2}, U_{3}\right),
$$

where: $U_{1}$ - the efficiency of the usage of human resources; $U_{2}$ - the efficiency of the usage of material resources and other property; $U_{3}$ - the efficiency of the usage of financial resources.

In terms of enterprise strategic management efficiency the measures and techniques creating the possibilities for the increase the efficiency of the usage of enterprise resources, as well as their application procedures have to be provided within the restructuring programme, i. e.:

$$
\begin{gathered}
U^{R}{ }_{1}=U^{0}{ }_{1}\left(\tau^{R}\right)=f\left(\lambda^{R}{ }_{1}, \phi^{R}\right)=U_{1}^{0}\left(\lambda_{1}^{0}, \phi^{0}\right) ; \\
\mathrm{U}_{2}^{R}=\mathrm{U}_{2}^{0}\left(\tau^{R}\right)=\mathrm{f}\left(\lambda^{R}{ }_{2}, \phi^{R}\right)=U_{2}^{0}{ }_{2}\left(\lambda^{0}, \phi^{0}\right) ; \\
\mathrm{U}_{3}^{R}=\mathrm{U}_{3}^{0}{ }_{3}\left(\tau^{R}\right)=\mathrm{f}\left(\lambda^{R}{ }_{3}, \phi^{R}\right)=U_{3}^{0}{ }_{3}\left(\lambda^{0}{ }_{3}, \phi^{0}\right) ;
\end{gathered}
$$

where the indices of restructured enterprise are the following: $U^{R}{ }_{1}$ - the efficiency indicator of the usage of human resources; $U_{2}^{R}-$ the efficiency indicator of the usage of material resources; $U^{R}{ }_{3}$ - the efficiency indicator of the usage of financial resources; $\lambda^{R}{ }_{1}=R / J-$ labor productivity $(R$ - sales in monetary terms, $J$ - number of employees); $\lambda^{R}{ }_{2}=R / T_{2}{ }^{a}-$ return on assets $\left(T_{2}{ }^{a}\right.$ - value of active share of assets (production measures); $\lambda^{R}$ - indicator of asset turnover; $\lambda_{3}^{R}$ - current liquidity ratio [23]. Respective indicators of not restructured enterprise are the following: $U^{0}{ }_{1}, U_{2}^{0}, U^{0}{ }_{3}, \lambda^{0}{ }_{1}$, $\lambda^{0}, \lambda^{0}{ }_{3}, \phi^{0}$.

Enterprise strategic analysis and the determination of objectives, strategy selection and programme preparation as well as its execution and evaluation of strategy implementation results are probably the essential tasks of strategic management. The combination of measures and techniques which let to increase the efficiency of execution of enterprise strategic management tasks could be expressed as following:

$$
\tau^{R}=\left\{\tau_{1}^{R} ; \tau_{2}^{R} ; \tau_{3}^{R} ; \tau_{4}^{R} ; \tau_{5}^{R} ; \tau_{6}^{R} ; \tau_{7}^{R}\right\},
$$

where: $\tau^{R}$ - the set of measures and techniques under restructuring programme for the efficiency increase of the following: enterprise strategy $\left(\tau^{R}\right)$; functional strategies $\left(\tau_{2}^{R}\right)$; management structure $\left(\tau^{R}{ }_{3}\right)$; management decision making organization $\left(\tau^{R}{ }_{4}\right)$; the usage of human $\left(\tau_{5}^{R}\right)$, material $\left(\tau_{6}^{R}\right)$, financial $\left(\tau^{R}\right)$ resources and other relevant property.

Due to the heterogeneousness of combination of qualitative or qualitative and quantitative features characteristic to the set $\tau^{R}$ it is proposed to evaluate the affect of the measures and techniques of this set to the enterprise strategic management efficiency using $\lambda^{R}{ }_{1}, \lambda^{R}$, $\lambda_{3}^{R}, \lambda^{R}$ indicators.

In the context of enterprise strategic management efficiency it is recommended to develop the following:

a) the possibilities for multifunctional application of resources;

b) the technological and production resources creating the competitive advantage.

In terms of security of resources creating the competitive advantage the level of concentration of enterprise management rights, endowing the authority to control and manage the enterprise, would provide the greater possibilities to control these resources and minimize the risk of their loss.

The possibilities of multifunctional application of enterprise resources, employing the technological and production resources creating the competitive advantage form conditions for the expedient change of enterprise strat- 
egy and its implementation techniques in the context of enterprise competitiveness in the markets. This is especially important trying to maintain or increase the enterprise market share in the markets receptive to innovations or subject to the products of relatively short life cycles (e.g. in the markets of information technologies, internet service, wireless communication, biotechnologies and, in certain cases food industry).

The results of application of this strategic management system improvement technique, when implementing restructuring programme of light-scale industrial enterprise show that enterprise is of disposition of measures creating the possibility to reach the level of strategic management efficiency which exceeds the

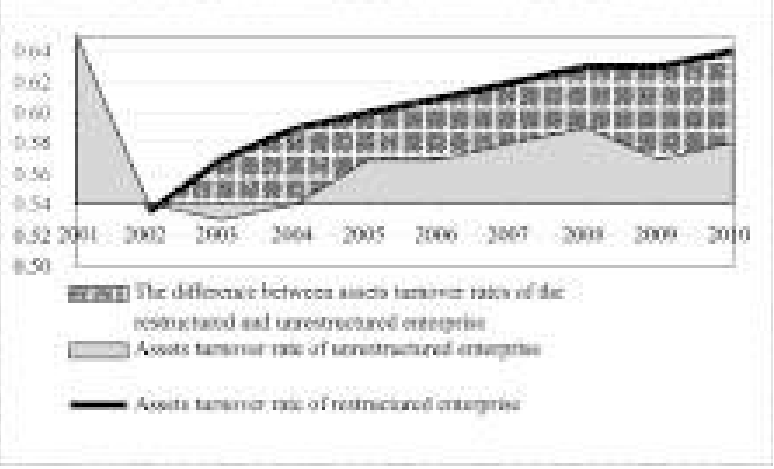

a) Asset turnover dynamics

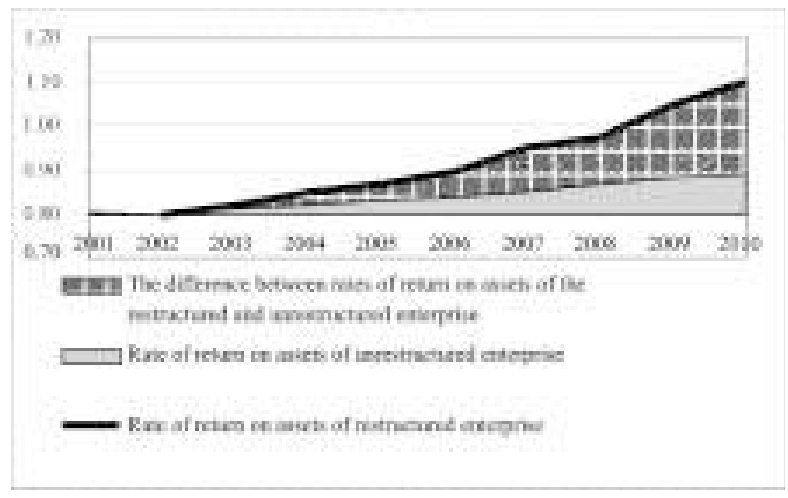

c) Return on assets dynamics one the enterprise have had before restructuring (Figure 1).

\section{THE RATIONALIZATION OF CORPORATE MANAGEMENT FUNCTIONS}

The rationalization of corporate management functions determines the specific of enterprise activity, i. e.: the strategy, the nature of product, its market and human, material and financial resources $[13,15,18,20]$. In order to rationalize corporate management for modeling the corporate management decisions (i. e.: strategic, administrative, functional, operational) and their possible combinations it is

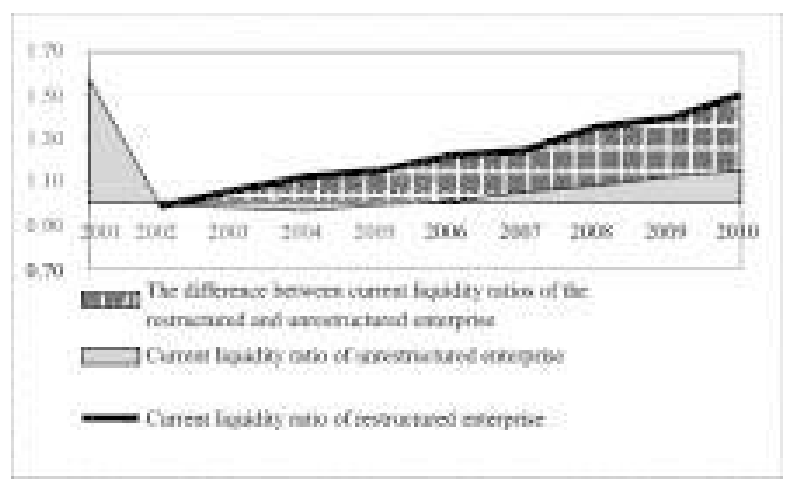

b) Current liquidity dynamics

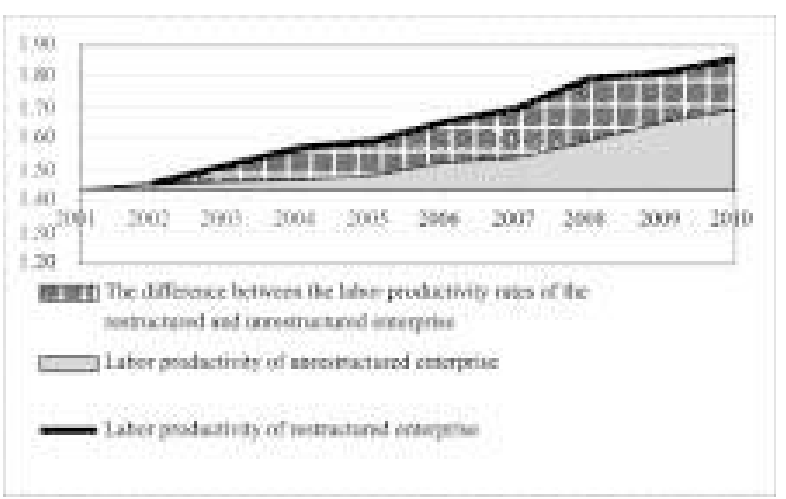

d) Labor productivity

Figure 1. Dynamics of efficiency of strategic management of enterprise: the restructured versus not restructured (restructuring period 2002-2003) 
necessary to evaluate the characteristics of enterprise products, the markets subject to the enterprise activity as well as the enterprise strategy and functional strategies, their interdependence. For instance, dependence of enterprise strategy efficiency on functional management decisions could be as following:

$$
S=f\left(S_{F 1}, \ldots, S_{F n}\right),
$$

where: $S$ - the efficiency of enterprise strategy; $S_{F i}=f\left(F_{1}, \ldots, F_{n}\right)-$ the efficiency of functional strategies (i. e.: finance, production, marketing, management of human resources and information flows $) ; F_{j}=f\left(O_{1}, \ldots, O_{n}\right)$ - the efficiency $F$ of function $j$ as to implement efficiently the functional strategy (to achieve the respective level of efficiency $S_{F i}$ of the functional strategy); $O_{1}, \ldots, O_{\mathrm{n}}$ - efficiency of operations as to implement efficiently function $j$ (to achieve respective level of the efficiency $F_{j}$ ( $j=1, \ldots, n)$ of the function).

In this context the efficiency of operation to be executed to implement efficiently function $j$ (to achieve respective level of the efficiency $F_{j}$ of the function) could be characterized as following:

$$
O_{j b}=f\left(w_{b 1}, w_{b 2}, w_{b 3}, w_{b 4}, w_{b 5}, w_{b 6}, w_{b 7}, w_{b 8}\right),(7)
$$

where the factors determining the efficiency of operation $b$ to be executed to implement function $j$ are the following: $w_{b 1}-$ number of employees, necessary to execute the operation; $w_{b 3}$ - input of time, necessary to execute the operation; $w_{b 8}=\sum_{i}\left(y_{b}^{j} / y_{n}^{j}\right)-$ homogeneity with respect to other operations of function $j\left(y_{b}^{j}-\right.$ characteristic of operation $b$ of function $j(b=$ $\left.w_{b 1}, \ldots, w_{b 7}\right) ; y_{n}^{j}-$ characteristics of operations $n$ of function $j ; n=1, \ldots, l)$.

The following indicators show the level of qualification of employees $\mathrm{w}_{\mathrm{b} 2}$ necessary to execute operation $b$ for function $j$; the level of specialization $\mathrm{w}_{\mathrm{b} 4}$; value of vertical/horizontal links with respect to other operations $\mathrm{w}_{\mathrm{b} 5}$; the need of information $w_{b 6}$; the standardization level of operation execution $\mathrm{w}_{\mathrm{b} 7}$ are proposed to be evaluated by scores (applying ten-point evaluation system).

In order to ensure the comparability of quantitative $\left(w_{b 1}, w_{b 3}, w_{b 8}\right)$ and qualitative $\left(w_{b 2}, w_{b 4}, w_{b 5}, w_{b 6}, w_{b 7}\right)$ indicators it is proposed for qualitative indicators to attribute the value of scores (applying ten-point evaluation system) having evaluated the significance of quantitative indicator on the basis of comparison of its quantitative value of the period considered with the average of its quantitative values per last three years of enterprise activity.

Having determined the values of factors of efficiency $O$ of operation $b$ of function $j$, the importance coefficients of these characteristics could be calculated in the following manner:

$$
Y_{p}=N_{p} / \sum_{p} N_{p}
$$

where: $Y_{p}$ - importance of value of indicator $p$; $N_{p}$ - value in scores of indicator $p$.

In the case of light-scale industrial enterprise, having characterized the strategic management functions of enterprise (Table 1) and compared them (Table 2) it was found, that it is expedient to improve the strategic management functions of enterprise as following:

a) managing finance means to ensure provision of information on time and reach maximal standardization of operations with respect to product $g=1$;

b) managing production has to apply product $g=1$ production organization techniques for product $g=2$ production in broader scale and ensure provision of information on time;

c) managing human resources must implement the measures increasing potential of human resources with respect to product $g=1$ and strengthen the links with other product $g=1$ strategic management functions; due to the homogeneity of operations of human resource management functions among products $g=1$ and $g=2$ it is expedient to use the human resource management techniques applied in the context of product $g=1$ for management of personnel working with product $g=2$; 

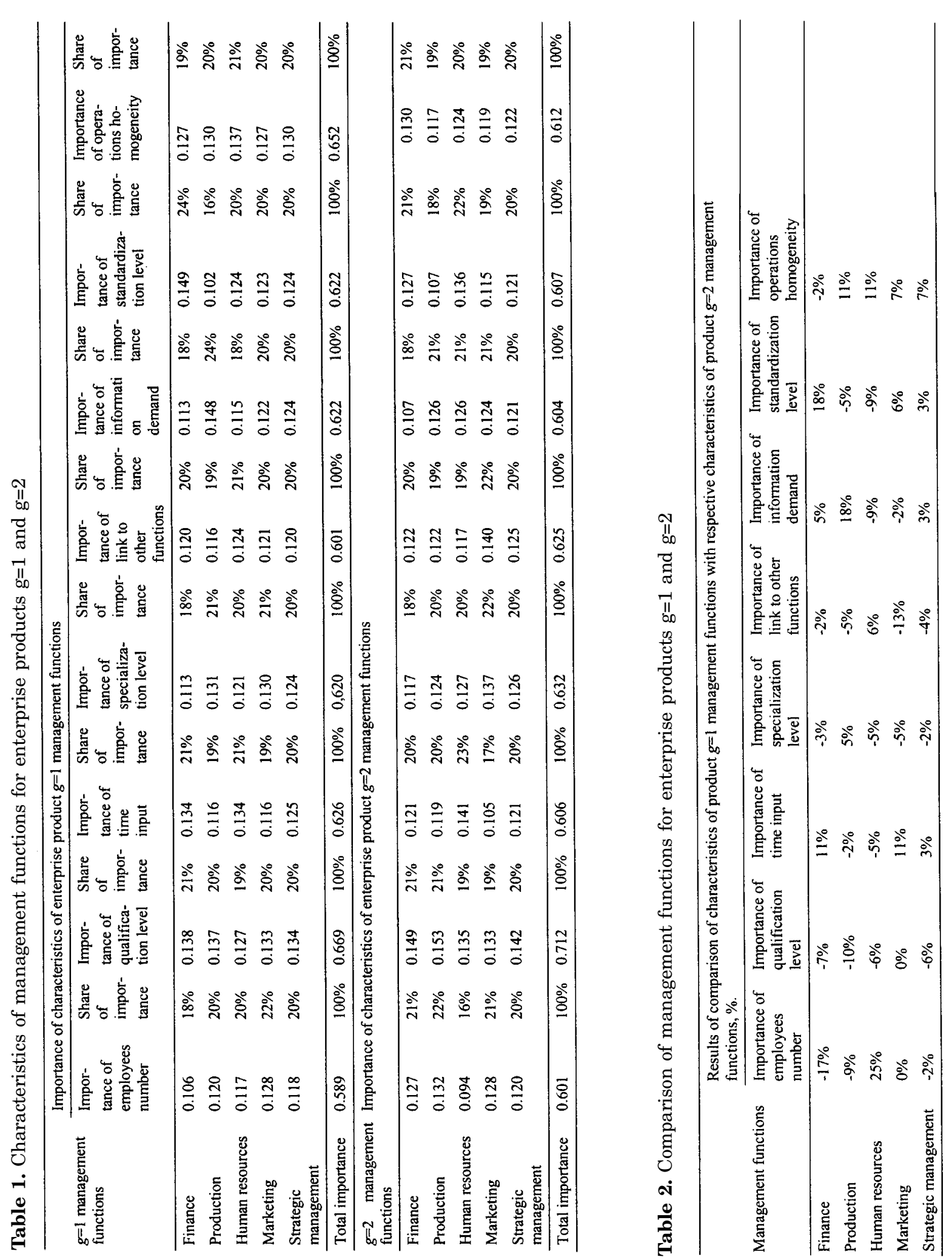
d) managing marketing means to increase standardization of operations of marketing functions of product $g=1$ and partially apply them in the process of development (production) and sale of product $g=2$; due to the importance of time input with respect of product $g=1$ it is expedient to ensure that this function is executed flexibly and operatively;

e) as to the strategic management it should to ensure (in the context of product $g=1$ ) that operations are executed flexibly, operatively, and information is provided on time; strategic management operations of product $g=1$ may be partially standardized and applied for product $g=2$ management.

Having identified values of enterprise business process management characteristics in terms of enterprise strategy efficiency it is necessary to evaluate the affect of enterprise product characteristics to the efficiency of enterprise strategy.

The efficiency of enterprise product could be characterized by these criteria:

$$
\begin{aligned}
& E_{g h}=f\left(z_{g 1}, z_{g 2}, z_{g 3}, z_{g 4}, z_{g 5}, z_{g 6}, z_{g 7},\right. \\
& \left.z_{g 8}, z_{g 9}, z_{g 10}, z_{g 11}, z_{g 12}\right),
\end{aligned}
$$

where the characteristics outlining efficiency $E$ of product $g(g=1, \ldots, m)$ in market $h(h=$ $1 . . l)$ are the following: competitiveness $z_{g 4}$; profitability $z_{g 5}$; market share $z_{g 6}$; number of segments $z_{g 7} ; z_{g 8}=\sum\left(y_{g j} / y_{n j}\right)$ - homogeneity $\left(y_{g j}-\right.$ characteristic $j$ of product $g(j=1, \ldots, m) ; y_{n j}$ characteristic $j$ of product $n ;(n=1, \ldots, l)$; financial $\left(z_{g 9}=T_{1 g} / T_{1} ; T_{1 g}\right.$ - the share of working capital used for product g development (production) and sale; $T_{1}-$ working capital), human $\left(z_{g 10}\right.$ $=C^{g}{ }_{z 10} / C^{g} ; C_{z 10}^{g}-$ costs of human resources used for product $\mathrm{g}$ development (production) and sale, $C^{g}$ - costs of product $g$ development (production) and sale), material $z_{g 11}=T_{2 i} / T_{2} ; T_{2 g}$ share of long-term assets used for product $\mathrm{g}$ development (production) and sale, $T_{2}$ - longterm assets) resources of enterprise, used for product g development (production) and sale.

Product competitiveness can be calculated in this manner [1, 14]:

$$
z_{g 4}=f\left(\gamma_{1}, \gamma_{2}, \gamma_{3}\right)
$$

where: $\gamma_{1}=\sum \zeta_{i} \gamma_{i}$ - cumulative indicator of competitivenéss of qualitative parameters; $\zeta_{i}$ value of qualitative parameter $i ; \gamma_{i}$ - comparative indicator of competitiveness under qualitative parameter $i$; $n$ - number of qualitative parameters subject to analysis. Product will be competitive under qualitative parameters if $\gamma_{1} \geq 1 ; \gamma_{2}=\sum \zeta_{j} \gamma_{j}$ - cumulative indicator of competitivehess of product development/production-sale cost parameters; $\zeta_{j}$ - value of product development/production-sale cost parameter $j$; $\gamma_{j}=\chi_{j} / \chi_{j 0},-$ comparative indicator of competitiveness under parameter $j$ of product development/production-sale cost; $\chi_{j}$ - value of parameter $j$ of product development/productionsale cost; $\chi_{j 0}$ - value of parameter $j$ of product development/production-sale cost of analogical product; $n$ - number of parameters of product development/production-sale cost subject to analysis. Product will be competitive under parameters of product development/productionsale cost if $\gamma_{2} \leq 1 ; \gamma_{3}=\prod_{k=1}^{m} \psi_{k}$; $(k=1, \ldots, m),-$ the indicator of competitiveness on conformity of product parameters with requirements of standards and norms (evaluation is based on scores - 1 point for conformity with the requirements and 0 - for opposite result); $\psi_{k}$ - evaluation of „hard“ parameter $k$ conformity with requirements of standards and norms; $m$ - number of „hard“ parameters subject to analysis; $\gamma_{3}$ - indicator of competitiveness on conformity of product parameters with requirements of standards and norms.

Profitability can be calculated as following:

$$
z_{g 5}=P / C,
$$

where: $P$ - net profit; $C$ - costs of sales.

Enterprise market share could be calculated in this manner:

$$
z_{g 6}=R / R_{K},
$$

where: $R$ - enterprise product sales (enterprise market share); $R_{K}$ - total product sales in the market. 


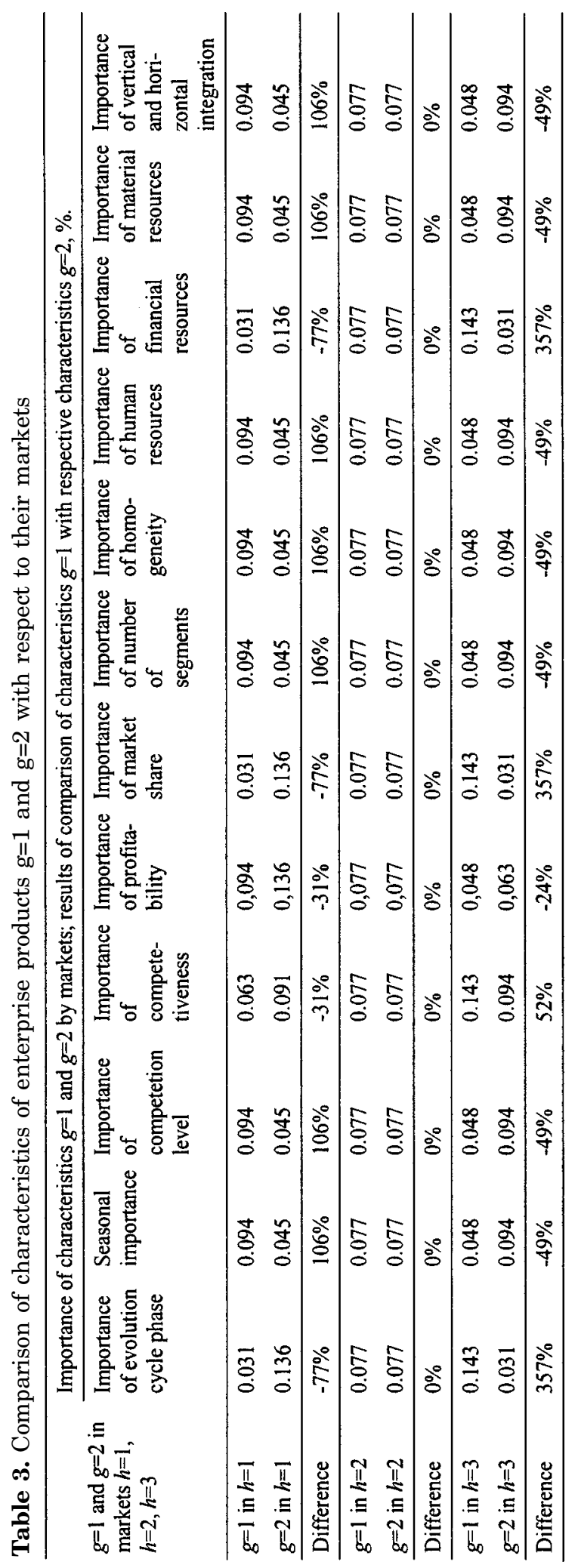


The number of competitors $z_{g 3}$ and segments $z_{g 7}$ can be easily identified having investigated the markets subject to the sale of enterprise products in quantitative terms.

The seasonal index $z_{g 2}$ can be calculated according to the equation [17]:

$$
Z_{g 2}=R^{g} / \mu_{t},
$$

where: $\mathrm{R}_{t}$ - sales of product $\mathrm{g}$ for considered period $(t=1, \ldots, \mathrm{n}) ; \mu_{t}-$ the average of values of product $g$ sales under considered time-series for respective period $t$.

The indicators (9) as evolution cycle phase (its significance) $z_{g 1}$, the ratio of vertical and horizontal integration $z_{g 12}$ for the development (production) and sale of products are expedient to evaluation using expert judgment (applying tenpoint evaluation system). The importance of values of product characteristics can be determined applying the 8th formula.

Having characterized the products of light-scale industrial enterprise and determined the importance of values of their characteristics as well as their dependence on markets, where these products are sold (Table 3) and having taken into account the above made conclusions on the affect of functional strategies of enterprise business management to the efficiency of light-scale industrial enterprise strategy the following was concluded:

a) in order to rationalize management of product $g=1$ in market $h=1$ it is expedient to apply innovative or adaptive management principles;

b) in order to rationalize management of $g=1$ product in $h=3$ market the principle of decentralized management can be applied;

c) it is expedient for products $g=1$ and $g=2$ in market $h=2$ to unify or, with respect to business development, apply principles of adaptive or innovative management.

Applying the techniques described in this paragraph the dominating characteristics of enterprise strategic management functions and their operations can be identified. On the basis of these characteristics the enterprise strategic management functions could be rational- ized at the level of enterprise and its functional departments or business units.

\section{SOLUTIONS FOR RESTRUCTURING CONTROL}

In order to achieve the rational management of restructuring programme implementation and its maximal benefit, it is necessary to ensure that restructuring measures are implemented rationally. In order to execute this task it is proposed to apply the technique (Table 4) which allows to evaluate the benefit of measures under implementation and to identify disadvantages of their application and reasons thereof.

Having compared the results of application of restructuring measures under implementation in the enterprise departments and business units (both in qualitative and in quantitative terms) with the planned ones set in the restructuring programmes and concluded that the benefit of those measures is not sufficient, it is necessary to ascertain the reasons of disadvantages of application of measures and form possible alternative solutions in order to change or improve the restructuring measures.

\section{CONCLUSIONS}

The proposed solutions for the management of corporate restructuring programmes give the following possibilities to the enterprises being restructured:

- to rationalize the strategic management of the enterprise, ensuring the effective utilization of the human, financial and material resources and other relevant strategic property, and the control of the main processes of the activity as well as its flexibility;

- to improve management of the enterprise, increasing the effectiveness of the management of the enterprise independent business units as well as the functional departments in the context of the competitiveness of the corporate as well as functional strategies; 
Table 4. Evaluation of benefit of measures during the implementation of restructuring

\begin{tabular}{|c|c|c|c|c|c|c|}
\hline \multirow[b]{2}{*}{ Task } & \multirow{2}{*}{$\begin{array}{l}\text { Planned } \\
\text { benefit }^{1}\end{array}$} & \multicolumn{5}{|c|}{ Benefit of application of measures under implementation ${ }^{2}$} \\
\hline & & $\begin{array}{l}\text { Independent } \\
\text { experts }\end{array}$ & Employees & Managers & Owners & Final result \\
\hline $\begin{array}{l}\text { 1. Managers actions creating and } \\
\text { improving management system }\end{array}$ & $\alpha_{l}$ & $\alpha_{l e}$ & $\alpha_{l d}$ & $\alpha_{l v}$ & $\alpha_{l s}$ & $\left(\alpha_{I e}+\alpha_{l d}+\alpha_{I \nu}+\alpha_{l s}\right) / 4$ \\
\hline 2. Product and service management & $\alpha_{2}$ & $\alpha_{2 e}$ & $\alpha_{2 d}$ & $\alpha_{2 v}$ & $\alpha_{2 s}$ & $\left(\alpha_{2 e}+\alpha_{2 d}+\alpha_{2 v}+\alpha_{2 s}\right) / 4$ \\
\hline 3. Customer relations management & $\alpha_{3}$ & $\alpha_{3 e}$ & $\alpha_{3 d}$ & $\alpha_{3 v}$ & $\alpha_{3 s}$ & $\left(\alpha_{3 e}+\alpha_{3 d}+\alpha_{3 \nu}+\alpha_{3 s}\right) / 4$ \\
\hline 4. Management of external partnerships & $\alpha_{4}$ & $\alpha_{4 e}$ & $\alpha_{4 d}$ & $\alpha_{4 v}$ & $\alpha_{4 s}$ & $\left(\alpha_{4 c}+\alpha_{4 d}+\alpha_{4 v}+\alpha_{4 s}\right) / 4$ \\
\hline 5. Management of financial resources & $\alpha_{5}$ & $\alpha_{5 e}$ & $\alpha_{5 d}$ & $\alpha_{5 v}$ & $\alpha_{s_{s}}$ & $\left(\alpha_{5 e}+\alpha_{5 d}+\alpha_{5 v}+\alpha_{5 s}\right) / 4$ \\
\hline 6. Management of long-term assets & $\alpha_{6}$ & $\alpha_{6 e}$ & $\alpha_{b d}$ & $\alpha_{6 v}$ & $\alpha_{6 s}$ & $\left(\alpha_{6 e}+\alpha_{6 d l}+\alpha_{6 v}+\alpha_{6 s}\right) / 4$ \\
\hline 7. Technology / production management & $\alpha_{7}$ & $\alpha_{7 e}$ & $\alpha_{7 d}$ & $\alpha_{7 v}$ & $\alpha_{7 s}$ & $\left(\alpha_{7 e}+\alpha_{7 d}+\alpha_{7 v}+\alpha_{7 s}\right) / 4$ \\
\hline $\begin{array}{l}\text { 8. Management of information and } \\
\text { knowledge systems }\end{array}$ & $\alpha_{8}$ & $\alpha_{8 e}$ & $\alpha_{8 d}$ & $\alpha_{8 v}$ & $\alpha_{8 s}$ & $\left(\alpha_{8 e}+\alpha_{8 r l}+\alpha_{8 v}+\alpha_{9 s}\right) / 4$ \\
\hline 9. Management of human resources & $\alpha_{g}$ & $\alpha_{g_{e}}$ & $\alpha_{g_{d}}$ & $\alpha_{q_{v}}$ & $\alpha_{9_{s}}$ & $\left(\alpha_{g_{e}}+\alpha_{g_{d}}+\alpha_{g_{v}}+\alpha_{g_{s}}\right) / 4$ \\
\hline Total value of results by evaluation group & & $\sum \alpha_{i e}$ & $\sum \alpha_{i d}$ & $\sum \alpha_{i v}$ & $\sum \alpha_{i s}$ & $\Sigma\left(\left(\alpha_{i e}+\alpha_{i d}+\alpha_{i v}+\alpha_{i s}\right) / 4\right)$ \\
\hline
\end{tabular}

\footnotetext{
${ }^{1}$ Indicator may be expressed in qualitative or quantitative terms.

${ }^{2}$ Level of achievements of the planned restructuring program results is evaluated using the following scores: " 2 " - great, "l" - medium, " 0 " - low.
}

- to control the restructuring process, evaluating the effect of the restructuring measures as with respect to the tactical as to the strategic levels of the corporate management (applying these measures for the rationalization of the set of the resources), correcting (improving, changing) the latter ones (the process of their implementation and the way and object of application) in order to increase efficiency of the utilization of the resources of the enterprise;

- to identify, justify and evaluate possibilities to increase efficiency of the enterprise activity and its development as well as perspective of the corporate strategy within the context of the competitive advantages;

- to attract under favorable conditions the external resources.

\section{REFERENCES}

[1] S.I. Abramov, Investments. Moscow: Center of Marketing Economy, 2000, 435 p. (In Russian).

[2] K.R. Andrews, Toward Professional Business Management, Harvard Business Review, March-
April, 1999, p. 52-61.

[3] H. I. Ansoff, Implementing Strategic Management. Prentice Hall, 1984. 378 p.

[4] R. N. Ashkenas, L. J. DeMonaco and S. C. Francis, Making the Deal Real: How GE Capital Integrates Acquisitions, Harvard Business Review, January-February, 1998, p. 64-73.

[5] M. Beer, N. Nohria, Cracking the Code of Change, Harvard Business Review, May-June, 2000, p. 133-141.

[6] J. Bivainis, A. Rastenienė and A. Tamošiūnas, Aspects of Enterprise Restructuring, Inžinerine ekonomika, No. 4(30), 2002, p. 51-56 (in Lithuanian).

[7] J. Bivainis, A. Tamošiūnas, Analysis of Enterprise Restructuring Goals, Ekonomika, No. 61, 2003, p. 7-18 (in Lithuanian).

[8] E. Bonabeau, Chr. Meyer, Swarm Intelligence. A Whole New Way to Think About Business, Harvard Business Review, May, 2001, p. 107114.

[9] A. Bosas, Corporate Strategies and Competitive Potential. Klaipèda: KU Publishing House, 2002. 294 p. (in Lithuanian).

[10] J. L. Bower, Not All M\&A are Alike - and That Matters, Harvard Business Review, March, 2001, p. 93-101. 
[11] J. Calof, The Mode Choice and Change Decision Process and Its Impact on International Performance, International Business Review, 2, 1993, p. 47-59.

[12] Cl. M. Christensen, M. Overdorf, Meeting the Challenge of Disruptive Change, Harvard Business Review, March-April, 2000, p. 67-76.

[13] R. L. Crum, I. Goldberg, Restructuring and Managing the Enterprise in Transition. Economic Development Institute of World Bank, 1998. 340 p.

[14] E. V. Chrucky, I. V. Kornejeva, Modern Marketing: Handbook for Market Research. Moscow: Finance and Statistics, 1999. 528 p. (in Russian).

[15] N. C. Churchill, J. W. Mullins, How Fast Can Your Company Afford to Grow? Harvard Business Review, May, 2001, p. 135-143.

[16] R. L. Daft, Organizational Theory and Design. $5^{\text {th }}$ ed. St. Paul: West Publishing, 1995. 342 p.

[17] B. J. Das, Managerial Economics. Kaunas: Technologija, 2000, 279 p. (in Lithuanian).

[18] L. E. Greiner, Evolution and Revolution as Organizations Grow, Harvard Business Review, May-June, 1998, p. 55-66.
[19] R. S. Kaplan, D. P. Norton, Having Trouble with Your Strategy? Then Map It, Harvard Business Review, September-October, 2000, p. 167-176.

[20] J. W. Pratt, Efficient Risk Sharing: The Last Frontier, Management Science Journal of the Institute of Operations Research and the Management Science, 46(12), December, 2000, p. 8194.

[21] R. G. Rajan, L. Zingales, The Firm as a Dedicated Hierarchy: a Theory of the Origins and Growth of Firms, Quarterly Journal of Economics, Volume CXVI, August, 2001, Issue 3, p. 74-87.

[22] M. E. Raynor, J. L. Bower, Lead from the Center. How to Manage Divisions Dynamically, Harvard Business Review, May, 2001, p. 93100.

[23] Results of Evaluation of Financial Condition of Enterprises for 1996-1999. Department of Statistics under Government of Lithuania, 2000. 156 p. (in Lithuanian).

[24] M. L. Rock, The Mergers \& Acquisitions. Handbook. McGraw-Hill Company, 1997. 425 p.

[25] M. Sawhney, Don't Homogenize, Synchronize, Harvard Business Review, July-August, 2001, p. 101-119. 